\title{
Necrotizing Fasciitis in Low Income Countries: About 23 Cases of Bujumbura Hospitals
}

\author{
Jean Claude Niyondiko ${ }^{1}$, Evrard Niyonkuru2 ${ }^{2}$, Gilbert Ndayizeye ${ }^{1}$, Stève Nimubona ${ }^{1}$, \\ Clovis Paulin Baramburiye ${ }^{2}$, Léodégal Bazira ${ }^{2}$
}

${ }^{1}$ Kamenge Teaching Hospital, Department of Trauma and Orthopedic Surgery, Bujumbura, Burundi

${ }^{2}$ Kamenge Teaching Hospital, Department of General Surgery, Bujumbura, Burundi

Email: *niyjcc@yahoo.fr

How to cite this paper: Niyondiko, J.C., Niyonkuru, E., Ndayizeye, G., Nimubona, S., Baramburiye, C.P. and Bazira, L. (2021) Necrotizing Fasciitis in Low Income Countries: About 23 Cases of Bujumbura Hospitals. Open Journal of Orthopedics, 11, 33-39. https://doi.org/10.4236/ojo.2021.112004

Received: December 25, 2020

Accepted: February 19, 2021

Published: February 22, 2021

Copyright $\odot 2021$ by author(s) and Scientific Research Publishing Inc. This work is licensed under the Creative Commons Attribution International License (CC BY 4.0)

http://creativecommons.org/licenses/by/4.0/

\begin{abstract}
Background: Necrotizing fasciitis is a rapidly spreading soft tissue infection involving the deep facial layers. It can cause secondary necrosis leading to significant morbidity and mortality. The most important predictor of mortality is a delay in diagnosis. In low income countries, that delay must be high and other predictors of morbidity and mortality must be pointed out. Objective: To determine necrotizing fasciitis (NF) prognostic factors in a low income country. Patients and Methods: It is a prospective and descriptive study conducted over a one-year period from November 1, 2017 to November 1, 2018 about 23 cases of necrotizing fasciitis in two hospitals of Bujumbura. Results: The incidence of necrotizing fasciitis in these 2 hospitals (Kamenge Teaching Hospital and Prince Regent Charles Hospital) was 1\%. The average age of patients was 41.76 years. Males were predominant with a sex ratio of 1.55. The risk factors for NF were: NSAIDs in 39\%; HIV infection in $13 \%$, diabetes mellitus in $4 \%$ and high blood pressure in $4 \%$. The average time from symptoms onset to admission was 17.13 days. The mean time from admission to surgical treatment was 4 days with extremes of 1 to 22 days. The most affected site was the lower limb in $82 \%$ of cases. All patients (96\%) were treated with necrotic tissue debridement. It was associated with skin grafting in $48 \%$ of cases. One patient (4\%) with diabetes mellitus and HIV infection was amputated. The mortality rate was $22 \%(n=5)$. Among those 5 patients, there was a combination of risk factors (diabetes mellitus, NSAID use and HIV infection) in $80 \%(\mathrm{n}=4), 60 \%(\mathrm{n}=3)$ were over 60 years of age and $60 \%$ $(\mathrm{n}=3)$ were operated 10 days after the onset of symptoms. The average time of hospital stay was 101 days with extremes of 14 to 400 days. Conclusion: Necrotizing fasciitis is associated with a high mortality rate in low income countries. The use of NSAIDs; delayed treatment, elderly and immunosuppressive conditions such as diabetes mellitus and HIV are the most prognostic factors in Bujumbura hospitals.
\end{abstract}




\section{Keywords}

Necrotizing Fasciitis, Prognosis, Low Income Countries

\section{Introduction}

Necrotizing fasciitis (NF) is a skin and soft tissue infection that involves the vital and functional prognosis of patients. Its management requires a multidisciplinary team [1]. It is often located in the lower limb but it can occur in any part of the body [2] [3]. Many bacteria can lead to that condition but the streptoccocci are the most frequently involved. The frequency of NF is strongly linked to the frequency of its risk factors such as diabetes mellitus, cancer, HIV, organ transplantation and alcoholism [4] [5]. The absence of an urgent and appropriate treatment compromises the prognosis of the disease. NF is responsible of serious functional sequelae in $20 \%-50 \%$ of cases [6] [7] and of a mortality rate between 6 and 76\% [8]. The earliness of the surgical procedure in the first 24 hours following admission is a major determinant of the prognosis. The initial severity of sepsis, elderliness and comorbidity are the main mortality risk factors [9]. These risk factors associated with NF vary from developed to low and middle income countries. This is probably due to the different lifestyles of populations. Knowing the factors that lead to the poor results of FN treatment is the population of Bujumbura will allow to anticipate the mechanisms for preventing and treating this pathology.

We analyze the prognostic factors associated with NF in patients at Kamenge Teaching Hospital and Prince Regent Charles Hospital in Bujumbura a main city of Burundi which is a low income country.

\section{Material and Methods}

This was a prospective and descriptive study conducted over a one-year period from November 1, 2017 to November 1, 2018. This study was carried out in the surgical departments of the 2 hospitals of Bujumbura (the Kamenge Teaching hospital and the Prince Regent Charles Hospital). All patients admitted for NF during the study period were included. After obtaining the authorization of the ethics committee and the consent of the patients; the data collection was carried out by direct questioning of the patients or their family and friends only from the follow-up sheets. They were collected on a pre-established form. Mortality, amputation and long hospital stay were considered as criteria for poor prognosis. The variables studied were age, sex, the time between the onset of symptoms and consultation, risk factors, the location of the NF, the time between admission and surgical treatment, the treatment provided at the hospital and the evolution of the cases. Data entry was done using Microsoft excel and averages were calculated using "Stata" software. The results are presented in numbers and percentages. 


\section{Results}

Twenty-three cases of NF were collated from a total of 2116 patients hospitalized in the surgical department of the CHUK and HPRC, that is about $1 \%$ of all cases admitted during the study period. The mean age of the patients was 41.76 years [(SD = 4.68)] [CI 95\% 32.05 - 51.48 Median = 42 (EIQ: 28 - 60)]. The age range of 31 - 60 years was the most represented with a frequency of $48 \%$ (Table 1(a)).

Males were predominant (61\%) with a sex ratio of $1.55 \%$. NSAIDs use was the most common risk factor in $39 \%$ of cases, followed by HIV in $13 \%$, diabetes mellitus in $4 \%$ and high blood pressure in $4 \%$ (Table $1(\mathrm{~b})$ ). The gateway to infection was identified in $43 \%$ of patients. The mean time from symptom onset to admission was 17.13 days [ $(\mathrm{SD}=1.91)$ 95\% CI: 13.18 - 21.09 Median 14 days (EIQ: 10 - 30)]. Thirteen patients (57\%) were referred from another health care facility. Cutaneous necrosis and painful edema were the reason for consultation in all our patients (100\%) (Figure 1). The lower limb was the most affected in nineteen cases $(82 \%)$ with one case $(4 \%)$ in which both lower limbs are affected, the upper limb is affected in three cases (13\%)(Table $1(\mathrm{c})$ ).

Dual antibiotic therapy combining beta-lactam antibiotics and imidazole was the most commonly prescribed combination of antibiotics (43\%). Debridement of all necrotic tissue up to macroscopic healthy limits was performed in all our patients (96\%). Concerning the reconstruction of skin loss, $65 \%$ of the cases,

Table 1. Epimiological features of necrotising fasciitis: Bujumbura; 2019. (a) Patients years ranges; (b) Risk factors of necrotising fasciitis; (c) Necrotising fasciitis location.

(a)

\begin{tabular}{ccc}
\hline years ranges & $\mathbf{n}$ & percentage \\
\hline$<1$ & 1 & $4 \%$ \\
$1-30$ & 5 & $22 \%$ \\
$31-60$ & 11 & $48 \%$ \\
$>60$ & 6 & $26 \%$ \\
\hline
\end{tabular}

(b)

\begin{tabular}{ccc}
\hline Risk factors & n & percentage \\
\hline HIV & 3 & $13 \%$ \\
NSAID use & 9 & $39 \%$ \\
Diabetis mellitus & 1 & $4 \%$ \\
Blood pressure & 1 & $4 \%$ \\
\hline
\end{tabular}

(c)

\begin{tabular}{ccc}
\hline Location & $\mathbf{n}$ & percentage \\
\hline Lower limbs & 19 & $82 \%$ \\
Upper limbs & 3 & $13 \%$ \\
Abdominal wall & 3 & $13 \%$ \\
\hline
\end{tabular}




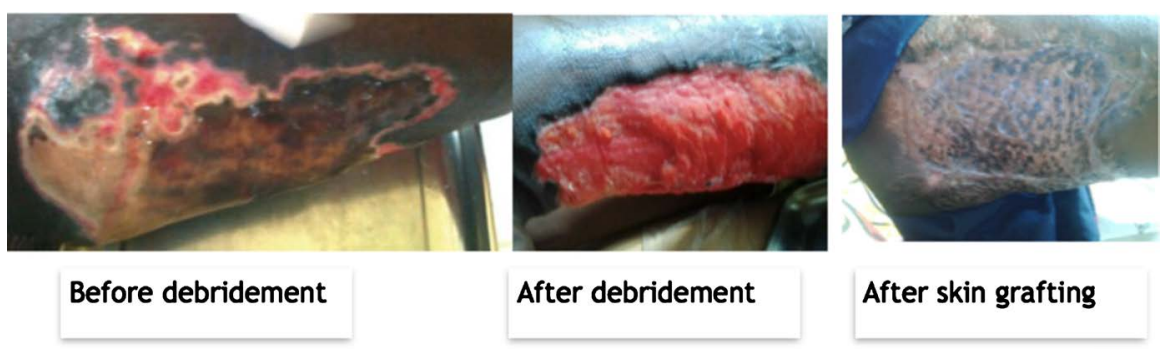

Figure 1. Lower limb necrotizing fasciitis.

have been treated by skin graft while for 7 patients (30\%) a directed healing was necessary. One patient (4\%) who was HIV infected and had used NSAIDs had extensive necrosis associated with severe sepsis. He was treated with an ATK amputation (Figure 1).

The mean time from admission to surgical treatment was 4.17 days with [(SD = 1.24) $95 \%$ CI: 1.60 - 6.75 Median 2 days (EIQ: 1 - 4)]. The mean time of hospital stay was 101 days with extremes ranging from 14 to 400 days. In $38 \%$ of patients who were hospitalized beyond 100 days, NSAIDs were found to be taken.

Five patients (22\%) died. Among these, 4 patients $(80 \%)$ had consulted more than 10 days after symptoms onset, 3 patients $(60 \%)$ had risk factors, among whom 2 (40\%) had HIV infection, 1 (20\%) taken NSAIDs and 3 (60\%) were over 60 years of age. Overall, there was a statistically significant relationship between patient prognosis and NSAIDs use, with a $\mathrm{P}$-value of $0.035(\mathrm{P}<0.05)$.

\section{Discussion}

The purpose of our study was to analyse the prognostic factors of NF in the two major hospitals in Bujumbura with unfortunately a small sample of patients as limitation. NF is a serious infection because of the functional sequelae it causes and the mortality rate associated with it. It accounts for $1 \%$ of the causes of surgical hospitalization in the two national hospitals in Bujumbura. In a study conducted in 2006 in Qatar, NF accounted for 1.15\% of all cases admitted to the surgical intensive care unit [10]. All ages are affected but with a peak of frequency in young adults. The average age of patients in our series is 41.76 years, and studies in advanced and low- and middle-income countries have found a mean age ranging UNE from 31 to 61 years [11] [12].

In our study, there is a predominance of males with a sex ratio of 1.55 . In the review of the literature, male predominance is found with a sex ratio varying between 1.4 and 3 [13] [14]. Nevertheless, a Canadian paediatric series noted a slight female predominance with a sex ratio of 0.9 [15].

The various causes of immunosuppression (diabetes, HIV, alcoholism, use of immunosuppressants) are risk factors for NF. These factors may lead to poor results by promoting the spread of necrosis, aggravating the infection and slowing the healing [16]. There is a disparity in their association with NF whether in sub-Saharan Africa or in the Western countries. HIV infection, being the main cause of immunosuppression in sub-Saharan countries, is strongly associated 
with NF according to the results of studies in this region. It is present in $13 \%$ of the cases in our study, in $17 \%$ of the cases in Magala, Uganda [12], while it is only associated with $4 \%$ in Germany [13].

Diabetes mellitus is the leading risk factor for NF in developed countries, with rates ranging from $46 \%$ to $71 \%$ [13] [17]. It is $4 \%$ in our series and $6 \%$ in the series of Magala et al. in Uganda and Yilma in Ethiopia. Hyperglycemia is a factor affecting adhesion, chemotaxis and bactericidal activity of phagocytes [15].

$\mathrm{NF}$ is a result of the alteration of the vascular framework and therefore hypertension is considered as a risk factor. In our series, it is associated with NF in $4 \%$ of cases. This association is stronger in Qatar (24.5\%) [10] and Saudi Arabia (46\%) [12].

NSAIDs represent the most prescribed therapeutic class in the world, given their analgesic, antipyretic and anti-inflammatory properties. The possibility that NSAIDs may contribute to the development or progression of NF has been raised. They mask the symptoms of NF or contribute directly to the pathogenesis of NF by inhibiting neutrophil function and increasing cytokine release [18]. The use of NSAIDs was found in $39 \%$ of our patients. NSAIDs use is also associated with long hospital stays, as $38 \%$ of patients who were hospitalized for more than 100 days had taken them.

The most affected site was the lower limb in $70 \%$ of cases. In the studies Surahio et al. in Saudi Arabia [12] and Magala et al. in Uganda in 2014 [11], the lower limb was most affected in $68.57 \%$ and $49 \%$ respectively.

Surgical treatment consisted of debridement in $96 \%$ of our patients. Several complementary therapeutic approaches (negative pressure therapy, hyperbaric chamber oxygen therapy, skin grafting), combined or not, allow rapid tissue reconstruction but only skin grafting was possible in our context. It was done in $48 \%$ of the cases. This treatment was performed with an average delay of 21.13 days. This delay in treatment is associated with the high mortality observed in our study. In fact, $80 \%$ of the patients who died consulted 10 days after the onset of symptoms. The average of the time of consultation for our patients was 17.13 days after the onset of symptoms, while the time between admission and surgical treatment was 4 days. One patient (4\%) with diabetes and HIV infection was amputated after failure of debridement.

There were five cases of death $(22 \%)$ in our series. According to studies in advanced and least developed countries, the mortality rate varies from $14 \%$ to $21 \%$ [4] [11] [14] [17]. In our series, the mortality rate increases with age. This is estimated to $37 \%$ in the age group of 50 to 60 years but raised to $62 \%$ after 60 years. Death and amputation are also associated with the use of anti-inflammatory drugs, HIV infection, and diabetes. Golger et al. [9] argue that advanced age and the existence of an immunosuppressive condition are predictive of mortality in patients with necrotizing fasciitis.

\section{Conclusion}

NF is a disease that affects middle-aged individuals with a male predominance. It 
affects the lower limbs mostly. It is often associated with different risk factors. In the two national hospitals in Bujumbura, it was often associated with the use of NSAIDs and HIV infection. The delay to admission induces a delay in surgical management, whereas surgical management, if undertaken early, can improve the functional and vital prognosis of this pathology. Advanced age and the existence of immunosuppressive conditions are risk factors of mortality, amputation and long stay at hospital.

\section{Conflicts of Interest}

The authors declare no conflicts of interest regarding the publication of this paper.

\section{References}

[1] Binder, J.P., Revol, M. and Servant, J.M. (2007) Dermohypodermites bactériennes nécrosantes et fasciites nécrosantes. Encyclpédie Médico-chirurgicale. Technique chirurgicale; Chirurgie Plastique, Reconstruction et esthétique, 2, 1-11.

[2] Netzer, G. and Fuchs, B.D. (2009) Necrotizing Fasciitis in a Plaster-Casted Limb: Case Report. American Journal of Critical Care, 18, 287-288. https://doi.org/10.4037/ajcc2009363

[3] Liu, Y.M., Chi, C.Y., Ho, M.W., Chen, C.M., Liao, W.C., Ho, C.M., Lin, P.C. and Wang, J.H. (2005) Microbiology and Factors Affecting Mortality in Necrotizing Fasciitis. Journal of Microbiology, Immunology and Infection, 38, 430-435.

[4] Cree, I. and Phiri, P. (2005) Necrotizing Fasciitis: A Deadly Disease. East and Central African Journal of Surgery, 10, 113-119.

[5] Roje, Z., Roje, Z., Matic, D., Librenjak, D., Dokuzovic, S. and Varvodic, J. (2011) Necrotizing Fasciitis: Literature Review of Contemporary Strategies for Diagnosing and Management with Three Case Reports: Torso, Abdominal Wall, Upper and Lower Limbs. World Journal of Emergency Surgery, 6, 46.

https://doi.org/10.1186/1749-7922-6-46

[6] Gauzlt, R. (2006) Infections cutanées graves: Définitions, caractéristiques cliniques et microbiologiques. Annales Françaises d Anesthésie et de Réanimation, 25, 967-970. https://doi.org/10.1016/j.annfar.2006.03.018

[7] Moet, G.J., Jones, R.N., Biedenbach, D.J., Stilwell, M.G. and Fritsche, T.R. (2007) Contemporary Causes of Skin and Soft Tissue Infections in North America, Latin America and Europe: Report from the Sentry Antimicrobial Surveillance Program (1998-2004). Diagnostic Microbiology and Infectious Diseases, 57, 7-13. https://doi.org/10.1016/j.diagmicrobio.2006.05.009

[8] McHenry, C.R., Piotrowski, J.J., Petrinic, D. and Malangoni, M.A. (2007) Determinants of Mortality in Necrotizing Soft Tissue Infections. Annals of Surgery, 221, 558-563. https://doi.org/10.1097/00000658-199505000-00013

[9] Golger, A., Ching, S., Goldsmith, C.H., et al. (2007) Mortality in Patients with Necrotizing Fasciitis. Plastic and Reconstructive Surgery, 119, 1803-1807. https://doi.org/10.1097/01.prs.0000259040.71478.27

[10] Shaikh, N. (2006) Necrotizing Fasciitis: A Decade of Surgical Intensive Care Experience. Indian Journal of Critical Care Medicine, 10, 225-229. https://doi.org/10.4103/0972-5229.29840

[11] Magala, J., Makobore, P., Makumbi, T., Kaggwa, S., Kalanzi, E. and Galukande, M. 
(2014) The Clinical Presentation and Early Outcomes of Necrotizing Fasciitis in a Ugandan Tertiary Hospital-A Prospective Study. BMC Research Notes, 7, 476-481. https://doi.org/10.1186/1756-0500-7-476

[12] Surahio, A.R., Khan, A.A., Farooq, M.U., Fatima, I. and Azhar, M.Z. (2009) Prevalence of Necrotizing Fasciitis during Ramadan and Hajj 1427-H. Journal of Ayub Medical College Abbottabad, 21, 125-129.

[13] Krieg, A., Röhrborn, A., Schulte am Esch, J., et al. (2009) Necrotizing Fasciitis: Microbiological Characteristics and Predictors of Post-Operative Outcome. European Journal of Medical Research, 14, 30-36. https://doi.org/10.1186/2047-783X-14-1-30

[14] Yilma, Y., Fikadu, Y. and Belachew, T. (2016) A Five-Year Review of Necrotizing Fasciitis at Jimma University Specialized Hospital, Jimma, Ethiopia. International Journal of Medicine and Medical Sciences, 8, 145-149.

https://doi.org/10.5897/IJMMS2016.1253

[15] Eneli, I. and Davies, H.D. (2007) Epidemiology and Outcome of Necrotizing Fasciitis in Children: An Active Surveillance Study of the Canadian Paediatric Surveillance Program. The Journal of Pediatrics, 151, 79-84. https://doi.org/10.1016/j.jpeds.2007.02.019

[16] Ecra, E.J., Kouassi, Y.I., Gbéry, I.P., et al. (2014) Comparative Study of Necrotizing Bacterial Dermohypodermitis or Necrotizing Fasciitis Depending on the HIV Serostatus in Abidjan (Côte d'Ivoire). Journal of Clinical \& Experimental Dermatology Research, 5, 234-237. https://doi.org/10.4172/2155-9554.1000234

[17] Dworkin, M., Westercamp, M., Park, L. and McIntyre, A. (2009) The Epidemiology of Necrotizing Fasciitis Including Factors Associated with Death and Amputation. Epidemiology and Infection, 137, 1609-1614. https://doi.org/10.1017/S0950268809002532

[18] Morgan, M.S. (2010) Diagnosis and Management of Necrotizing Fasciitis: A Multiparametric Approach. Journal of Hospital Infection, 75, 249-257. 